\title{
A Review of the Biotechnological Production of Methacrylic Acid
}

\author{
Juliana Lebeau, John P. Efromson and Michael D. Lynch* \\ Department of Biomedical Engineering, Duke University, Durham, NC, United States
}

Industrial biotechnology can lead to new routes and potentially to more sustainable production of numerous chemicals. We review the potential of biobased routes from sugars to the large volume commodity, methacrylic acid, involving fermentation based bioprocesses. We cover the key progress over the past decade on direct and indirect fermentation based routes to methacrylic acid including both academic as well as patent literature. Finally, we take a critical look at the potential of biobased routes to methacrylic acid in comparison with both incumbent as well as newer greener petrochemical based processes.

\section{OPEN ACCESS}

Edited by:

Lucia Gardossi,

University of Trieste, Italy

Reviewed by:

Sujit Jagtap,

University of Illinois at Urbana-Champaign, United States Farshad Darvishi,

University of Maragheh, Iran

*Correspondence:

Michael D. Lynch michael.lynch@duke.edu

Specialty section:

This article was submitted to Industrial Biotechnology,

a section of the journal Frontiers in Bioengineering and Biotechnology

Received: 22 January 2020 Accepted: 02 March 2020 Published: 20 March 2020

Citation:

Lebeau J, Efromson JP and Lynch MD (2020) A Review of the Biotechnological Production of Methacrylic Acid.

Front. Bioeng. Biotechnol. 8:207. doi: 10.3389/fbioe.2020.00207
Keywords: methacrylic acid, methyl-methacrylate, fermentation, sustainability, bioprocessing

\section{INTRODUCTION}

Methacrylic acid (MA) and its ester (methyl methacrylate, MMA) are primarily polymerized into polymethylmethacrylate (PMMA) which is used in the production of acrylic glass (Dormer et al., 1998). Acrylic glass is used in components of electronics, automobile parts, lights (LEDs), signs, and displays (Brydson, 1999; Nagai and Ui, 2004; Ali et al., 2015) ${ }^{1}$. Notably, PMMA has a high biocompatibility and low acute toxicity enabling use in medical applications (Frazer et al., 2005). MMA pricing ranges from $\$ 1.75$ to $\$ 2.25 / \mathrm{kg}^{2,3,4}$ with an annual market that will exceed $\$ 8$ billion USD by 2025 , growing at a rate of $8-9 \%$ per year.

This increasing demand for MA is not only due to increased demand for acrylic glass, but also the increasing number of new applications for MMA (Brydson, 1999). MMA will continue to be a critical monomer in the future with currently no equivalent replacement (Ali et al., 2015). As demand will continue to grow, more sustainable methods of production need to be considered. Numerous efforts have been made to increase sustainability and reduce waste in petrochemical processes. Recent advances in chemical processes have enabled alternative petrochemical feedstocks and reduced waste (Johnson et al., 2009; Witczak et al., 2010). Additionally, the International Energy Agency in 2012 designated MA as a suitable target for the design of a bio-based process (Burk and Van Dien, 2016) ${ }^{1}$.

Both petrochemical processes and biobased routes have their own strengths and weaknesses. In this review, we discuss the current states of and recent advances in both petrochemical and biobased routes to MMA. We review different bio-based routes as well as the performance requirements of

\footnotetext{
${ }^{1}$ PMMA Market Size Worth $\$ 8.16$ Billion By 2025|CAGR: 8.4\%. https://www.grandviewresearch.com/press-release/globalpolymethyl-methacrylate-pmma-industry.

${ }^{2}$ PMMA Production, Price and Market Demand. Plastics Insight https://www.plasticsinsight.com/resin-intelligence/resinprices/pmma/.

${ }^{3}$ https://dataweb.usitc.gov/

${ }^{4}$ https://www.plasticsinsight.com/resin-intelligence/resin-prices/pmma/ and https://www.grandviewresearch.com/pressrelease/global-polymethyl-methacrylate-pmma-industry
} 


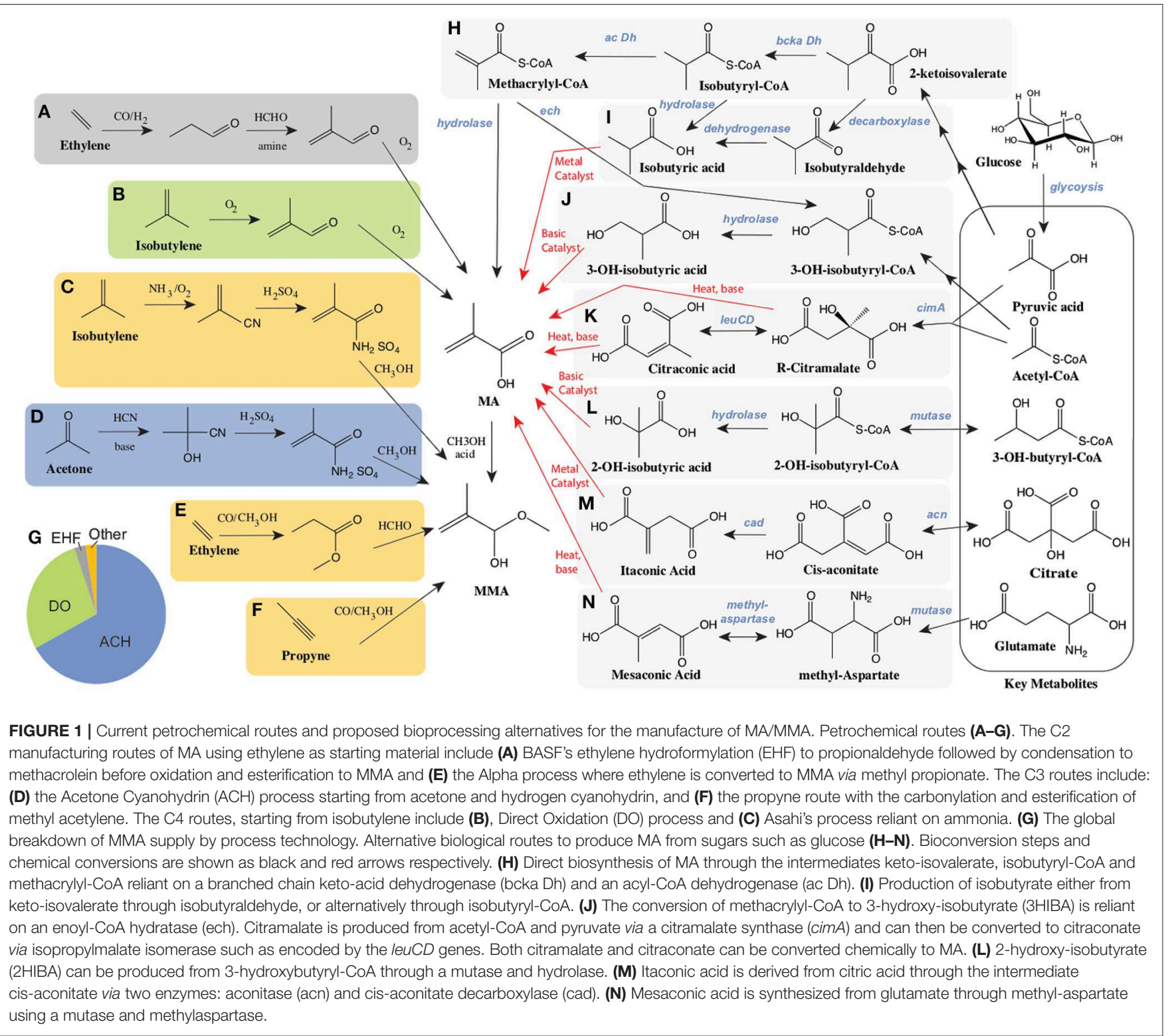

any biobased process to compete with advanced petrochemical technologies. Lastly, we discuss the potential of future bio-based routes to MMA as well as the key barriers for a bioprocess to compete with petrochemistry including conversion yields and feedstock costs.

\section{PETROCHEMICAL ROUTES}

Currently, MMA is produced via one of several processes from a few key petrochemical feedstocks as illustrated in Figures 1A-G. Over $65 \%$ of MMA is produced via the Acetone CyanoHydrin $(\mathrm{ACH})$ route, developed in the 1930's (Figure 1D) (Nagai and Ui, 2004). The use of toxic hydrogen cyanide, as well as concentrated acids are a primary concern with the $\mathrm{ACH}$ route, as is the negative impact of significant waste (ammonium bisulfate) generation and treatment (Nagai and Ui, 2004; Mahboub et al., 2018). A competitive route, Direct Oxidation (and similar processes), relies on isobutylene as a feedstock (Figure 1B) and is primarily commercial in Asia (Nagai and Ui, 2004; The Chemical Engineer, 2008; Mahboub et al., 2018). Concerns over safety, costs, and the environmental impact of the $\mathrm{ACH}$ route have driven efforts to find alternative routes to produce MMA (Adom et al., 2014). Important among these is the hydroformylation of ethylene and related chemistry (Figures 1A,E). The low costs of ethylene compared to acetone and isobutylene, as well as decreased waste and lower investment costs have made these processes attractive. In 2019, there were announcements related to the potential construction of new MMA plants using ethylene as a feedstock. If constructed these plants would be operational between 2024 and 2026 (Sale, 2019). 


\section{BIOPROCESSING ALTERNATIVES}

The use of biotechnology to provide alternative routes for the production of chemicals has had several successful outcomes (Chen et al., 2013; Valdehuesa et al., 2013; Van Dien, 2013; Barton et al., 2015; De Carvalho et al., 2018). Fermentation based routes to MMA utilizing more sustainable feedstocks represent one potential alternative to petrochemistry. Biobased routes may provide both long term environmental and economic sustainability. Given the competitiveness of the market, the development of biobased PMMA has become a priority of many of the current producers (ChiMei Corp., Mitsubishi Corp., Evonik Ind., Sumitomo Chemicals and Arkema) (Bio PMMA Market Trends, 2017) ${ }^{1,5}$. Previous work on the conversion of sugar to MA or MMA using engineered biocatalysts has focused on the evaluation or development of one of several pathways, as illustrated in Figures $1 \mathbf{H}-\mathbf{N}$, ranging from the direct production of MA to the combined use of biochemical and traditional chemistry to produce MA from glucose. In these bio-chemocatalytic routes, key intermediates are produced biologically and subsequently converted to MA. Intermediates evaluated to date include both 2- and 3- hydroxyisobutyric acids, which are converted to MA via dehydration, as well as several 5 carbon organic acids (citraconic, citramalic, itaconic, and mesaconic acids), which have the potential to be converted to MA either by decarboxylation or decarboxylation along with dehydration using an inexpensive hot pressurized water process. (Figures 1K,M,N) Significant work over the past decade on these routes has been made in the development of a variety of microorganisms for the biological production of target intermediates, as well as in their subsequent chemical conversions to MA. We will discuss each route in turn.

\section{Direct Production of Methacrylic Acid}

As illustrated in Figure $\mathbf{1 H}$, there is a direct route from glucose to MA. The biochemical steps involved are primarily derived from valine catabolism, via the natural intermediate methacrylyl-CoA (Bachhawat et al., 1957; Rendina and Coon, 1957; Massey et al., 1976). In valine catabolism, methacrylylCoA is hydrated to 3-hydroxyisobutyryl-CoA, hydrolysed to 3-hydroxyisobutyrate (Figure 1J) and subsequently oxidized to methylmalonate semialdehyde, which enters central metabolism through another oxidation to propionyl-CoA (Bachhawat et al., 1957). Bypassing the later steps of valine degradation by expression of a $\mathrm{CoA}$ hydrolase/thioesterase with engineered activity on methacrylyl-CoA, can lead to the direct production of MA. Numerous enzymes have been proposed to perform the conversion of methacrylyl-CoA to MA, which may all need to be engineered for this activity (Burgard et al., 2009). Despite these theoretical descriptions no production has been demonstrated (Burgard et al., 2009). To our knowledge, only one study of microbial bioproduction of MA from glucose was reported reaching a titer of $170 \mathrm{uM}(14.6 \mathrm{mg} / \mathrm{L})$ in shake flasks (Eastham

\footnotetext{
${ }^{5}$ Synthetic and Bio PMMA Market Size - Industry Share Report 2022. Global Market Insights, Inc. https://www.gminsights.com/industry-analysis/synthetic-and-biobased-pmma-polymethyl-methacrylate-market-size.
}

et al., 2018). In this work expression of an acyl-CoA oxidase (ACX4) converts isobutyryl-CoA to methacrylyl-CoA, which is transformed to MA via a promiscuous thioesterase (Hayashi et al., 1999; Eastham et al., 2018).

One potential reason for so little success in the biosynthesis of MA is likely due to its acute toxicity. In E. coli the concentration of MA reducing growth rate by $50 \%$ is only $13.2 \mathrm{mM}(1.1 \mathrm{~g} / \mathrm{L})$ (Webb et al., 2018). The toxicity of MA, its esters, and methacryly-CoA has been investigated in numerous in vivo studies in both eukaryotes and prokaryotes. The main mechanisms identified were the radical reactivity of MA and derivatives with cellular nucleophiles such as glutathione. MA has also been shown to directly induce DNA damage and inhibit key metabolic enzymes (Plaga et al., 2000; Ansteinsson et al., 2013; Arya et al., 2013; Curson et al., 2014; Murakami et al., 2019). This toxicity makes its direct biological production highly limited in any of the potential microbial hosts considered. (Lipscomb et al., 2011, 2012; Jarboe et al., 2013; Lam et al., 2014; Mukhopadhyay, 2015).

\section{Isobutyric Acid}

As depicted in Figures 1H,I, another route to MA leveraging valine catabolism relies on the biological production of isobutyric acid (IBA), with subsequent oxidation to MA. This route is attractive as significant progress has been made to date on IBA production in engineered hosts. A recent study highlights that $S$. cerevisiae naturally possesses an Ehrlich pathway (Yu et al., 2016), which enables it to produce isobutyrate. However, reported titers of IBA (387.4 mg/L) (Yu et al., 2016) remain relatively low. In contrast, IBA synthesis from glucose in engineered E. coli has been reported at titers of $90 \mathrm{~g} / \mathrm{L}$, volumetric productivities of $1 \mathrm{~g} / \mathrm{L}-\mathrm{h}$, and yields of $0.39 \mathrm{~g} \mathrm{IBA} / \mathrm{g}$ glucose ( $80 \%$ of the theoretical maximum) (Zhang et al., 2011; Xiong et al., 2015). In this work, isobutyraldehyde was first produced from 2-keto-isovalerate using an $\alpha$-ketoisovalerate decarboxylase (kivd) from Lactococcus lacti, followed by oxidation to IBA utilizing a phenylacetaldehyde dehydrogenase ( $p a d A$ ) from E. coli (Zhang et al., 2011; Xiong et al., 2015). While these bioprocesses are promising, achieving high chemical conversion yields have proven more challenging. Dehydrogenation has been performed on both IBA to produce MA as well as on methyl-IBA to produce MMA. To date yields of only 40 and $60 \%$, respectively, have been demonstrated. Yields are limited by significant byproduct (carbon dioxide and diisopropyl ketone) formation (McDaniel and Young, 1963; Wilhelm Gruber and Ginter Schröder, 1983; Macho et al., 2004).

\section{Hydroxy Isobutyric Acids}

Routes through biosynthesized hydroxy-isobutyrates (HIBAs) can be coupled with dehydration reactions to produce MA and are considered as alternative chemical conversions to the dehydrogenation of IBA (Figures 1J,L). Both 3-hydroxyisobutyrate (3-HIBA), derived from valine catabolism as discussed above, as well as its isomer 2-hydroxy-isobutyrate (2HIBA), have been considered as biological end products (Volker and Schindelmann, 1969; Burgard et al., 2009; Rohwerder and Müller, 2010; Dubois et al., 2011; Burk et al., 2012; Marx et al., 2016). The conversion of 3-HIBA to MA has been reported 
with conversions from 20 to $>90 \%$ (Volker and Schindelmann, 1969; Marx et al., 2016) while the dehydration of 2-HIBA has been accomplished at conversion yields of $71.5 \%$ (Pirmoradi and Kastner, 2017). As mentioned above, 3-HIBA is a natural intermediate in valine catabolism. Engineering efforts have resulted in 3-HIBA titers ranging from $150 \mathrm{mg} / \mathrm{L}$ (Dellomonaco et al., 2011) to $2.3 \mathrm{~g} / \mathrm{L}$ (Lang et al., 2015), often produced along with significant amounts of IBA (Lang et al., 2014; Xiong et al., 2015; Jawed et al., 2016; Marx et al., 2016).

2-HIBA-CoA (Figure 11) was originally found to be a natural metabolite in a pathway that has evolved in the biodegradation of tert -butyl ether (Rohwerder et al., 2006). The production of 2-HIBA-CoA via a mutase from A. tertiaricarbonis is dependent on a B12-dependent mutase involving free radical isomerization (Yaneva et al., 2012; Kurteva-Yaneva et al., 2015). In addition, this enzyme has stereospecificity for (S)-3-hydroxybutyryl-CoA as a substrate (Kurteva-Yaneva et al., 2015). While (R)-3-hydroxybutyryl-CoA, a precursor to polyhydroxyalkanoates, is readily produced from acetoacetylCoA in numerous organisms (Madison and Huisman, 1999; Chen and Jiang, 2017), (S)-3-hydroxybutyryl-CoA and (S)-3hydroxyacyl-CoAs more generally are intermediates in fatty acid biosynthesis. Engineering of pathways with (S)-3-hydroxyacylCoA intermediates have been a focus in the production of alcohols as well as fatty acids (Dellomonaco et al., 2011; Lynch et al., 2014; Kim et al., 2015; Wang et al., 2019). 2HIBA has been produced from both (S)-3-hydroxybutyrylCoA, via mutases similar to that originally characterized, as well as (R)-3-hydroxybutyryl-CoA through the discovery of (R) specific mutases. $(\mathrm{R})$ specific mutases are also vitamin $\mathrm{B} 12$ dependent. Biocatalysis reliant on B12 dependent enzymes often require vitamin supplementation, and can suffer from enzyme inactivation, requiring reactivation (Daniel et al., 1998; Mori and Toraya, 1999). To date 2-HIBA biosynthesis has been reported in engineered microbes at titers as high as $6.4 \mathrm{~g} / \mathrm{L}$ (Burgard et al., 2009; Hoefel et al., 2010; Reinecke et al., 2011; Soucaille and Boisart, 2011; Rohde et al., 2017).

\section{Citramalic/Citraconic Acids}

Citramalate is a naturally occurring diacid and an intermediate in the isoleucine biosynthesis pathway of some anaerobic bacteria (Buckel and Barker, 1974; Howell et al., 1999; Risso et al., 2008). Citramalate is synthesized from the central metabolites pyruvic acid and acetyl-CoA using a single enzyme, citramalate synthase $(\operatorname{cim} A)$, as depicted in Figure 1K. This enzyme has been successfully utilized in pathways enabling the biosynthesis of 1propanol and 1-butanol through the intermediate citramalate. In these studies directed evolution of citramalate synthase resulted in feedback resistant mutants with improved activity (Atsumi and Liao, 2008). Citramalate has limited toxicity to microbes when compared to MA where concentrations of $\sim 25 \mathrm{~g} / \mathrm{L}$ are required to inhibit growth by $50 \%$ (Webb et al., 2018). Citramalate can be converted to MA via a relatively simple process involving simultaneous decarboxylation and dehydration with citraconate as an intermediate. The simplest conversion uses only hot pressurized water and has achieved conversion yields as high as $81 \%$ (de Jong et al., 2012). Although this chemistry is inexpensive, catalyst development may be needed to improve yields and selectivity. Recent successes in bioengineering highlight the potential of citramalate as an intermediate to MA. Using engineered E. coli expressing a mutant citramalate synthase, titers ranging from $46.5 \mathrm{~g} / \mathrm{L}$ to as high as $80 \mathrm{~g} / \mathrm{L}$ have been reported with yields of $58 \%$ of theoretical (Johnson et al., 2009; Wu and Eiteman, 2016; Parimi et al., 2017; Webb et al., 2018). Additionally, significant systems characterization of these engineered strains has been reported (Webb et al., 2019).

\section{Itaconic Acid}

Itaconic acid has long been produced via biotechnology primarily utilizing wild type or engineered Aspergillus terreus strains (Steiger et al., 2013; Hevekerl et al., 2014; Bafana and Pandey, 2018; Kuenz and Krull, 2018). Itaconic acid is also produced from citrate through the intermediate cis-aconitate which is decarboxylated to itaconate as illustrated in Figure 1M. Titers in the range of 120-220 g/L have been reported with itaconate yields ranging from 0.45 to as high as $0.58 \mathrm{~g}$ itaconic acid/g glucose and maximal production rates from 0.45 to $1 \mathrm{~g} / \mathrm{L}-\mathrm{h}$ (Hevekerl et al., 2014; Huang et al., 2014; Krull et al., 2017a; Tehrani et al., 2019). In addition, the chemical decarboxylation of itaconic acid to MA has been demonstrated via several different catalytic routes, mostly reliant on metal catalysts. Some of these processes have demonstrated conversion yields as high as $40 \%$ at over $90 \%$ selectivity (Le Nôtre et al., 2014; Lansing et al., 2017; Bohre et al., 2019). However, the current cost of itaconic acid ranges from $\$ 1.80$ to $\$ 2.00 / \mathrm{kg}$ (Kuenz and Krull, 2018), which is similar to the price of MMA. At this pricing and $100 \%$ conversion of itaconic acid to MA (with loss of carbon dioxide), a price of $\$ 2.70-\$ 3.00 / \mathrm{kg}$ could be expected for MA alone (not including the cost of esterification). This is $20-70 \%$ higher than estimated petrochemical based pricing for MA. The route to MA through itaconic acid may well be the most mature, with previous scale up and commercial production but key improvements to reduce costs would include improving the yield of fermentation, as well as increasing the volumetric rate of production by at least 2 fold (Bafana and Pandey, 2018). Recent efforts have been aimed at engineering organisms beyond A. terreus including U. maydis, $Y$. lipolytica, and E. coli (Krull et al., 2017b; Tehrani et al., 2019; Zhao et al., 2019).

\section{Mesaconic Acid}

Lastly, another attractive potential route to MA is through mesaconic acid. Mescaconic acid is produced from the amino acid glutamate. Glutamic acid production via fermentation is a mature technology, primarily reliant on engineered Corynebacterium glutamicum (Kimura, 2003; Wendisch et al., 2016). Mesaconate production relies on several natural pathways for glutamate catabolism and/or carbon fixation (Figure 1N), wherein a mutase converts glutamate to methyl aspartate, which through the action of a methyl aspartase is converted to mesaconate (Wang and Zhang, 2015). Similarly to the HIBACoA mutase described above, the glutamate mutase is also a B12 dependent enzyme reliant on free radical chemistry and requires vitamin supplementation and continuous enzyme reactivation (Chih and Marsh, 2000; Wang and Zhang, 2015). Methyl 
TABLE 1 | Comparison of maturity and challenges for biobased routes to MA.

\begin{tabular}{|c|c|c|c|c|}
\hline Maturity & Route & Best demonstrated performance & $\begin{array}{l}\text { Bioprocess } \\
\text { challenges }\end{array}$ & Chemistry challenges \\
\hline 1 & Itaconic acid/decarboxylation & $\begin{array}{l}\text { 220g/L (U. maydis) (Tehrani et al., 2019) } \\
0.45 \text { g/L-h } \\
51 \% \text { bioprocess yield } \\
48 \% \text { conversion to MA (Johnson et al., 2009, 2012; } \\
\text { Pirmoradi and Kastner, 2017) }\end{array}$ & Fermentation rates \& yields & Yield, catalyst costs \\
\hline 2 & $\begin{array}{l}\text { Citramalic acid/decarboxylation } \\
\text { \& dehydration }\end{array}$ & $\begin{array}{l}80 \mathrm{~g} / \mathrm{L} \text { (E. coli) (Webb et al., 2018) } \\
1.85 \mathrm{~g} / \mathrm{L}-\mathrm{h} \\
58 \% \text { bioprocess yield } \\
81 \% \text { conversion to MA (Johnson et al., 2009, 2012; } \\
\text { Pirmoradi and Kastner, 2017) }\end{array}$ & Fermentation rates \& yields & Yield, catalyst development \\
\hline 3 & Isobutyric acid/dehydrogenation & $\begin{array}{l}90 \mathrm{~g} / \mathrm{L} \text { (E. coli) (Xiong et al., 2015) } \\
0.625 \mathrm{~g} / \mathrm{L}-\mathrm{h} \\
80 \% \text { bioprocess yield } \\
40-60 \% \text { conversion to MA (Pirmoradi and Kastner, 2017) }\end{array}$ & Fermentation rates \& yields & Catalyst development \\
\hline 4 & 2-HIBA/dehydration & $\begin{array}{l}\text { 6.4g/L (C. necator H16) (Hoefel et al., 2010) } \\
0.09 \mathrm{~g} / \mathrm{L}-\mathrm{h} \\
6.3 \% \text { bioprocess yield } \\
71.5 \% \text { conversion to MA (Pirmoradi and Kastner, 2017) }\end{array}$ & Enzymology & Yield, catalyst development \\
\hline 5 & Mesaconic acid/decarboxylation & $\begin{array}{l}\text { 23g/L (E. coli) (Wang et al., 2018) } \\
0.36 \text { g/L-h } \\
64 \% \text { bioprocess yield } \\
52 \% \text { conversion to MA (Pirmoradi and Kastner, 2017) }\end{array}$ & Enzymology & Yield, catalyst development \\
\hline 6 & Methacrylic acid production & $\begin{array}{l}0.0146 \mathrm{~g} / \mathrm{L}(E . \text { coli) (Eastham et al., 2018) } \\
0.0007 \mathrm{~g} / \mathrm{L}-\mathrm{h} \\
0.62 \% \text { bioprocess yield }\end{array}$ & $\begin{array}{l}\text { Rates, yields, engineering } \\
\text { resistance }\end{array}$ & NA \\
\hline
\end{tabular}

aspartase shares a reaction mechanism with aspartases converting aspartate to fumarate (de Villiers et al., 2012). Heterologous expression of these enzymes from C. tetanomorphum in E. coli enabled mesaconic acid titers approaching $23 \mathrm{~g} / \mathrm{L}$ (Wang and Zhang, 2015; Wang et al., 2018). The same basic chemical conversions producing MA from citramalate can convert mesaconic acid to MA although yields still require optimization and possible catalyst/process development (Johnson et al., 2012). While glutamate is basically a commodity chemical in its own right with prices estimated from $\$ 1.70-\$ 1.95 / \mathrm{kg}(\$ 2.00-2.25 / \mathrm{kg}$ of monosodium glutamate $)^{3}$, assuming a yield of MA from glutamate of $0.58 \mathrm{~g} / \mathrm{g}$, one could predict a potential MA cost of $\sim \$ 2.90 / \mathrm{kg}$ which is not competitive with current pricing for MA. Cost reductions in glutamate production will be needed for this route to be competitive.

\section{FUTURE OUTLOOK}

We can, admittedly subjectively, assess the relative maturity and remaining technical challenges for each of the proposed fermentation based routes to MA, as given in Table 1. In our opinion, the three most promising routes, when considering both the strain and bioprocess development, as well as final chemical conversions, are the routes through itaconic, citramalic, and isobutyric acids. All of these routes are well past proof of concept stages, but still will require optimization.

While Table 1 has attempted to rank order the maturity of possible biobased routes to MA, all of the potential biological routes for MA from sugar, as described above, have a similar yield, 1 mole of MA from 1 mole of hexose, which translates in the case of glucose to a maximal theoretical yield of 0.477 gram of MA per gram of glucose. This yield is a common challenge to all of these routes. At theoretical yield, and glucose costs of $\$ 0.20 / \mathrm{lb}(\$ 0.44 / \mathrm{kg})^{6,7}$ this translates to a cost of $\$ 0.92 / \mathrm{kg}$ of MA for feedstock alone. This represents a major challenge to these biological routes, wherein they not only need to compete with the $\mathrm{ACH}$ manufacturing technology, but also newer ethylene based processes. In the case of the $\mathrm{ACH}$ process, converting acetone $(\$ 0.94 / \mathrm{kg}), \mathrm{HCN}(\$ 0.66 / \mathrm{kg})$ and sulfuric acid $(\$ 0.13 / \mathrm{kg})$ to MMA, we can estimate the cost of feedstocks for MA (which is not isolated as an intermediate in this process) at roughly $\$ 1 / \mathrm{kg}^{3}$. In this case, on a feedstock cost basis, glucose based routes have the potential to compete. However, the greener petroleum based routes converting ethylene $(\$ 0.76 / \mathrm{kg})$, syngas $\left(\mathrm{CO} / \mathrm{H}_{2}, \$ 0.07 / \mathrm{kg}\right)$, and methanol $(\$ 0.37 / \mathrm{kg})$ or formaldehyde $(\$ 0.63 / \mathrm{kg})$ to MA (Figures 1A,E), would have estimated costs for feedstocks of only $\$ 0.50 / \mathrm{kg}$ of $\mathrm{MA}^{3}$. This is half that of biobased routes, discussed in Figure 1.

While the proposed routes to MA have a maximal yield of 0.477 gram of MA per gram of glucose, there is room for improvement. The theoretical yield for MA from glucose is $\sim 0.63 \mathrm{~g} / \mathrm{g}$. A key limitation of these pathways is the wasting of electrons, as illustrated in Figure 2. While we often use the term "renewable carbon," it is in actuality usually renewable reducing

\footnotetext{
${ }^{6}$ The Sweet and Sour History of Sugar Prices|Winton. Winton https://www.winton. com/longer-view/the-sweet-and-sour-history-of-sugar-prices.

${ }^{7}$ Sugar Prices - 37 Year Historical Chart. https://www.macrotrends.net/2537/
} sugar-prices-historical-chart-data. 

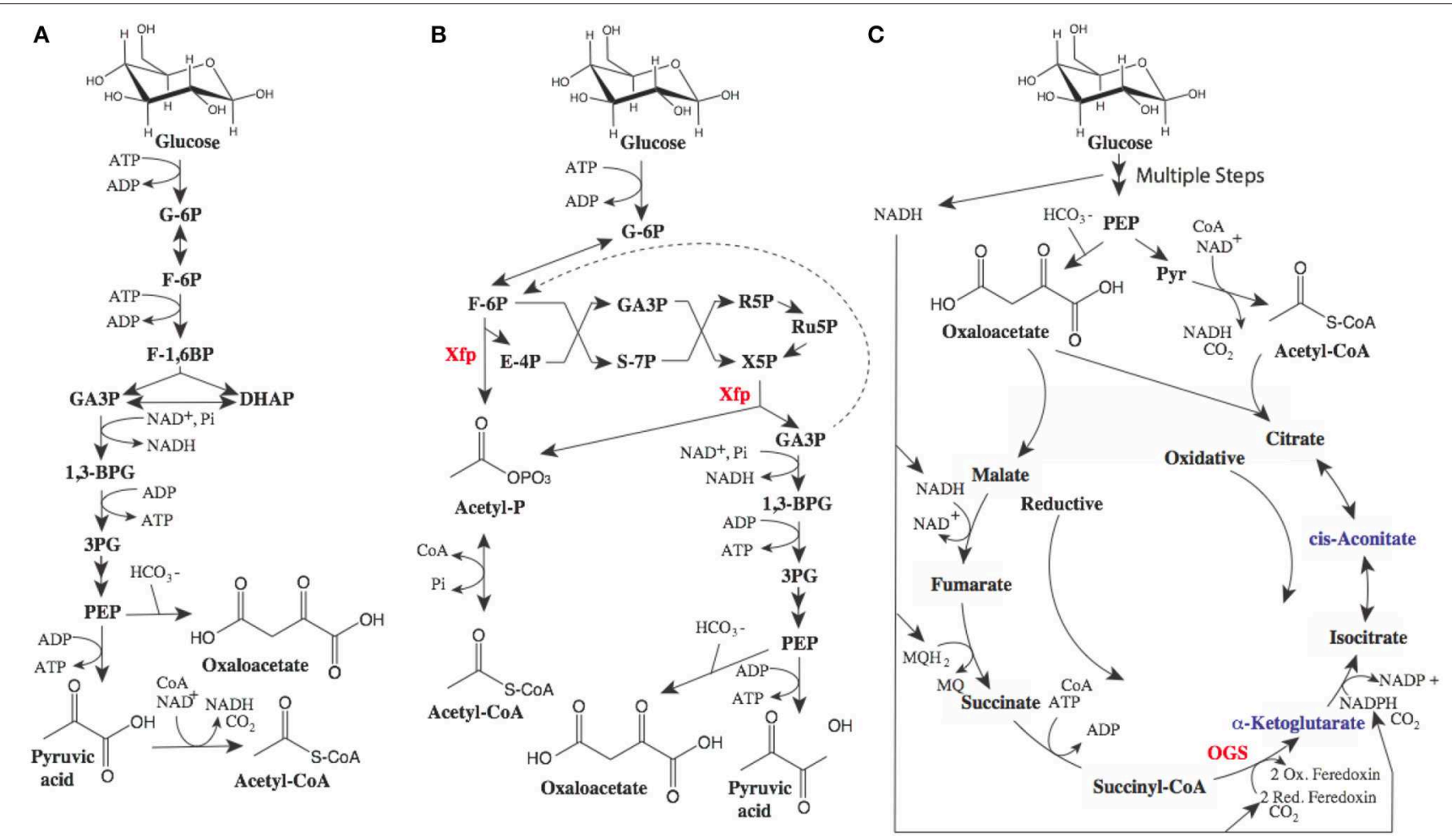

FIGURE 2 | Potential metabolic pathways to optimize MA yields. (A) glycolytic metabolism, (B) Bifidobacterium shunt, and (C) reductive TCA cycle. In glycolysis (A) 0.5 moles of glucose are converted to 1 mole of pyruvate (or alternatively 1 mole of oxaloacetate) and one mole of NADH (1 pair or electrons). Pyruvate can be oxidized to acetyl-CoA generating another mole of NADH. (B) The Bifidobacterium shunt phosphoketolase enzyme (xfp) (Fandi et al., 2001) has activity as both an erythrose-4-phosphate (E4P) and xylulose-5-phosphate (X5P) phosphoketolase producing acetyl-phosphate (acetyl-P). Recycling 2 moles of

glyceraldehyde-3-phosphate (GA3P) through triosephosphate isomerase and the reversible fructose bisphosphate aldolase can lead to improved yield (dashed line) (C). Inclusion of 2-oxoglutarate synthase (OGS) in anaerobic production could lead metabolism where oxidative flux through the TCA cycle is balanced by reductive flux wherein electrons from glycolysis are consumed. Balanced TCA flux can lead to higher yields of alpha-ketoglutarate derived products such as mesaconic acid as well as cis-aconitate derived products such as itaconic acid. Additional abbreviations: glucose-6-phosphate (G-6P), fructose-6-phosphate (F-6P),

fructose-1,6-bisphosphate (F-1,6BP), dihydroxyacetone phosphate (DHAP), 1,3 bisphosphoglycerate (1,3BPG), 3 phosphoglycerate (3PG), phosphoenolpyruvate (PEP).

equivalents or electrons which are of the most value. The current biobased routes to MA described above all produce excess electrons. These electrons need to be oxidized for metabolism and production to proceed, either aerobically using oxygen, or anaerobically with another electron acceptor requiring the committed formation of unwanted fermentation byproducts. In addition, wasted pairs of electrons are accompanied by wasted carbon.

Fortunately, potential metabolic solutions to improve yields have been described, generally relying on the use of multiple metabolic routes in combination. For example, the combination of oxidative routes (described above) where excess electrons are generated and reductive routes where excess electrons can be utilized, can lead to improved yields. A good example of an oxidative route to the intermediate acetyl-CoA would be the bifidobacterium shunt, or non-oxidative glycolysis, as depicted in Figure 2B (Bogorad et al., 2013; Lin et al., 2018). This metabolic shunt has the potential to produce acetyl-CoA while conserving electrons and carbon, increasing maximal yields. In the best case (where some of the three carbon intermediates can be recaptured in the oxidative pathway, dashed line Figure 2B), maximal yields of MA reach theoretical yields of $0.63 \mathrm{~g} / \mathrm{g}$. Non-oxidative glycolysis is useful for the routes to MA utilizing acetyl-CoA or pyruvate and acetyl-CoA (Figure 1). When evaluating the routes reliant on tricarboxylic acid (TCA) cycle intermediates or derivatives, consuming excess electrons produced via glycolysis in a reductive route can increase yields as demonstrated in Figure 2C. This would require expression of key enzymes from a natural reductive TCA cycle including 2-oxoglutarate synthase [OGS, which it should be noted is an oxygen sensitive enzyme (Hughes et al., 1998)]. A similar approach was used to increase 1,4-butanediol yield from TCA intermediates, albeit not requiring OGS (Yim et al., 2011). Again, this metabolism has the potential to increase theoretical yields of MA (from the mesaconic or itaconic acid intermediates) to the theoretical maximum of $0.63 \mathrm{~g} / \mathrm{g}$.

With maximal yields of $0.63 \mathrm{~g} / \mathrm{g}$, sugar costs of less than $\$ 0.32 / \mathrm{kg} \quad(\$ 0.145 / \mathrm{lb})$ would still be needed for biobased routes to have feedstock costs comparable to newer ethylene based petrochemical processes. Sugar costs are a challenge in the bioeconomy in general, particularly for biobased commodities and especially for biofuels (Chen et al., 2013; 
NREL, 2013; Taylor et al., 2015; Rosales-Calderon and Arantes, 2019). These costs may well be achievable with second generation cellulosic based sugars as technologies for their production mature (Youngs and Somerville, 2012; Kühner, 2013; Liu et al., 2019). Previous estimates suggest cellulosic sugars can reach costs as low as $\$ 0.26 / \mathrm{kg}$ (Soare, 2013). Future changes in the legislative landscape, including potential carbon taxes or fines, may also help biobased routes compete (Rajni et al., 2006; Mustafa and Balat, 2009; Information Technology and Innovation Foundation, 2018; EPA, 2019). However, it is likely that technical developments to increase yields (as well as rates and titers), lower sugar costs, and legislative changes will be required for any potential biobased process to MA or MMA to take hold in the market.

\section{REFERENCES}

Adom, F., Dunn, J. B., Han, J., and Sather, N. (2014). Life-cycle fossil energy consumption and greenhouse gas emissions of bioderived chemicals and their conventional counterparts. Environ. Sci. Technol. 48, 14624-14631. doi: $10.1021 /$ es503766e

Ali, U., Khairil, J., and Buang, N. A. (2015). A review of the properties and applications of Poly (Methyl Methacrylate) (PMMA). Polymer Rev. 55, 678-705. doi: 10.1080/15583724.2015.1031377

Ansteinsson, V., Kopperud, H. B., Morisbak, E., and Samuelsen, J. T. (2013). Cell toxicity of methacrylate monomers-the role of glutathione adduct formation. J. Biomed. Mater. Res. 101, 3504-3510. doi: 10.1002/jbm.a.34652

Arya, A. S., Lee, S. A., and Eiteman, M. A. (2013). Differential sensitivities of the growth of Escherichia coli to acrylate under aerobic and anaerobic conditions and its effect on product formation. Biotechnol. Lett. 35, 1839-1843. doi: 10.1007/s10529-013-1282-7

Atsumi, S., and Liao, J. C. (2008). Directed evolution of Methanococcus jannaschii citramalate synthase for biosynthesis of 1-propanol and 1butanol by Escherichia coli. Appl. Environ. Microbiol. 74, 7802-7808. doi: 10.1128/AEM.02046-08

Bachhawat, B. K., Coon, M. J., Kupiecki, F. P., Nagle, R., and Robinson, W. G. (1957). Coenzyme A thiol esters of isobutyric, methacrylic, and betahydroxyisobutyric acids as intermediates in the enzymatic degradation of valine. J. Biol. Chem. 224, 1-11.

Bafana, R., and Pandey, R. A. (2018). New approaches for itaconic acid production: bottlenecks and possible remedies. Crit. Rev. Biotechnol. 38, 68-82. doi: 10.1080/07388551.2017.1312268

Barton, N. R., Burgard, A. P., Burk, M. J., Crater, J. S., Osterhout, R. E., Pharkya, P., et al. (2015). An integrated biotechnology platform for developing sustainable chemical processes. J. Ind. Microbiol. Biotechnol. 42, 349-360. doi: $10.1007 /$ s10295-014-1541-1

Bio PMMA Market Trends (2017). Statistics, Research Report 2022 - Fractovia.org. Available online at: https://www.fractovia.org/news/industry-research-report/ synthetic-and-bio-based-pmma-polymethyl-methacrylate-market (accessed Febraury 21, 2020).

Bogorad, I. W., Lin, T.-S., and Liao, J. C. (2013). Synthetic non-oxidative glycolysis enables complete carbon conservation. Nature 502, 693-697. doi: 10.1038/nature12575

Bohre, A., Novak, U., Grilc, M., and Likozar, B. (2019). Synthesis of biobased methacrylic acid from biomass-derived itaconic acid over barium hexa-aluminate catalyst by selective decarboxylation reaction. Mol Catalysis 476:110520. doi: 10.1016/j.mcat.2019.110520

Brydson, J. A. (ed.). (1999). "Acrylic plastics". In: Plastics Materials, 7th Edn. (Elsevier), 398-424. doi: 10.1016/B978-075064132-6/50056-5

Buckel, W., and Barker, H. A. (1974). Two pathways of glutamate fermentation by anaerobic bacteria. J. Bacteriol. 117, 1248-1260. doi: 10.1128/JB.117.3.1248-1260.1974

\section{AUTHOR CONTRIBUTIONS}

JE extracted 10 year average chemical prices from the United States International Trade Commission (https:// dataweb.usitc.gov/). JL, JE, and ML wrote, revised, and edited the manuscript.

\section{FUNDING}

The authors declare that this study received funding from DMC Biotechnologies, Inc. The funder was not involved in the study design, collection, analysis, interpretation of data, the writing of this article or the decision to submit it for publication. We would also like to acknowledge the following support: ONR YIP \#12043956, and DOE EERE grant \#EE0007563.

Burgard, A. P., Burk, M. J., Osterhout, R. E., and Pharkya, P. (2009). Microorganisms for the Production of Methacrylic Acid. Patent No US8241877B2. Genomatica, Inc.

Burk, M. J., Burgard, A. P., Osterhout, R. E., Sun, J., and Pharkya, P. (2012). Microorganisms for Producing Methacrylic Acid and Methacrylate Esters and Methods Related Thereto. Patent No US9133487B2. Genomatica, Inc.

Burk, M. J., and Van Dien, S. (2016). Biotechnology for chemical production: challenges and opportunities. Trends Biotechnol. 34, 187-190. doi: 10.1016/j.tibtech.2015.10.007

Chen, G.-Q., and Jiang, X.-R. (2017). Engineering bacteria for enhanced polyhydroxyalkanoates (PHA) biosynthesis. Synth. Syst. Biotechnol. 2, 192-197. doi: 10.1016/j.synbio.2017.09.001

Chen, X., Zhou, L., Tian, K., Kumar, A., Singh, S., Prior, B. A., et al. (2013). Metabolic engineering of Escherichia coli: a sustainable industrial platform for bio-based chemical production. Biotechnol. Adv. 31, 1200-1223. doi: 10.1016/j.biotechadv.2013.02.009

Chih, H.-W., and Marsh, E. N. G. (2000). Mechanism of glutamate mutase: identification and kinetic competence of acrylate and glycyl radical as intermediates in the rearrangement of glutamate to methylaspartate. J. Am. Chem. Soc. 122, 10732-10733. doi: 10.1021/ja002488+

Curson, A. R. J., Burns, O. J., Voget, S., Daniel, R., Todd, J. D., McInnis, K., et al. (2014). Screening of metagenomic and genomic libraries reveals three classes of bacterial enzymes that overcome the toxicity of acrylate. PLoS ONE 9:e97660. doi: 10.1371/journal.pone.0097660

Daniel, R., Bobik, T. A., and Gottschalk, G. (1998). Biochemistry of coenzyme B12-dependent glycerol and diol dehydratases and organization of the encoding genes. FEMS Microbiol. Rev. 22, 553-566. doi: 10.1111/j.1574-6976.1998.tb00387.x

De Carvalho, J. C., Magalhaes, A. I., and Soccol, C. R. (2018). Biobased itaconic acid market and research trends-Is it really a promising chemical. Chim. Oggi-Chem. Today 36, 56-58.

de Jong, E., Higson, A., Walsh, P., and Wellisch, M. (2012). Bio-based chemicals value added products from biorefineries. IEA Bioenergy, Report. Available online at: https://www.ieabioenergy.com/wp-content/uploads/2013/10/Task42-Biobased-Chemicals-value-added-products-from-biorefineries.pdf

de Villiers, M., Puthan Veetil, V., Raj, H., de Villiers, J., and Poelarends, G. J. (2012). Catalytic mechanisms and biocatalytic applications of aspartate and methylaspartate ammonia lyases. ACS Chem. Biol. 7, 1618-1628. doi: $10.1021 /$ cb3002792

Dellomonaco, C., Clomburg, J. M., Miller, E. N., and Gonzalez, R. (2011). Engineered reversal of the $\beta$-oxidation cycle for the synthesis of fuels and chemicals. Nature 476, 355-359. doi: 10.1038/nature 10333

Dormer, W, Gomes, R, Meek, M. E, World Health Organization and International Programme on Chemical Safety (1998). Methyl Methacrylate. World Health Organization. Available online at: https:/apps.who.int/iris/handle/10665/ 42030 
Dubois, J.-L., Okumura, K., Kobayashi, Y., and Hiraoka, R. (2011). Improved Process of Dehydration Reactions. Patent No US9914699B2. Arkema.

Eastham, G. R., Stephens, G., and Yiakoumetti, A. (2018). Process for the Biological Production of Methacrylic Acid and Derivatives Thereof. Patent No US20180171368A1. Lucite International UK Ltd.

EPA (2019). The economics of climate change. Finance Dev. 56. Available online at: https://www.imf.org/external/pubs/ft/fandd/2019/12/pdf/fd1219.pdf

Fandi, K. G., Ghazali, H. M., Yazid, A. M., and Raha, A. R. (2001). Purification and N-terminal amino acid sequence of fructose-6-phosphate phosphoketolase from Bifidobacterium longum BB536. Lett. Appl. Microbiol. 32, 235-239. doi: 10.1046/j.1472-765X.2001.00895.x

Frazer, R. Q., Byron, R. T., Osborne, P. B., and West, K. P. (2005). PMMA: an essential material in medicine and dentistry. J. Long Term Eff. Med. Implants 15, 629-639. doi: 10.1615/JLongTermEffMedImplants.v15.i6.60

Hayashi, H., Iwata, K., Matsuoka, M., Hayashi, H., Takemiya, T., Yasuda S., et al. (1999). A novel acyl-CoA oxidase that can oxidize shortchain acyl-CoA in plant peroxisomes. J. Biol. Chem. 274, 12715-12721. doi: $10.1074 /$ jbc.274.18.12715

Hevekerl, A., Kuenz, A., and Vorlop, K.-D. (2014). Influence of the $\mathrm{pH}$ on the itaconic acid production with Aspergillus terreus. Appl. Microbiol. Biotechnol. 98, 10005-10012. doi: 10.1007/s00253-014-6047-2

Hoefel, T., Wittmann, E., Reinecke, L., and Weuster-Botz, D. (2010). Reaction engineering studies for the production of 2-hydroxyisobutyric acid with recombinant Cupriavidus necator H 16. Appl. Microbiol. Biotechnol. 88, 477-484. doi: 10.1007/s00253-010-2739-4

Howell, D. M., Xu, H., and White, R. H. (1999). (R)-citramalate synthase in methanogenic archaea. J. Bacteriol. 181, 331-333. doi: 10.1128/JB.181.1.331-333.1999

Huang, X., Lu, X., Li, Y., Li, X., and Li, J.-J. (2014). Improving itaconic acid production through genetic engineering of an industrial Aspergillus terreus strain. Microb. Cell Fact. 13:119. doi: 10.1186/s12934-014-0119-y

Hughes, N. J., Clayton, C. L., Chalk, P. A., and Kelly, D. J. (1998). Helicobacter pylori porCDAB and oorDABCGenes encode distinct pyruvate: flavodoxin and 2-Oxoglutarate: acceptor oxidoreductases which mediate electron transport to NADP. J. Bacteriol. 180, 1119-1128. doi: 10.1128/JB.180.5.1119-1128. 1998

Information Technology and Innovation Foundation (2018). Carbon Tax Could Support Innovation and Economic Growth While Lowering Cost to Reduce Carbon. Emissions: New ITIF Report Finds.

Jarboe, L. R., Royce, L. A., and Liu, P. (2013). Understanding biocatalyst inhibition by carboxylic acids. Front. Microbiol. 4:272. doi: 10.3389/fmicb.2013. 00272

Jawed, K., Mattam, A. J., Fatma, Z., Wajid, S., Abdin, M. Z., Yazdani, S. S., et al. (2016). Engineered production of short chain fatty acid in Escherichia coli using fatty acid synthesis pathway. PLOS ONE 11:e0160035. doi: 10.1371/journal.pone.0160035

Johnson, D. W., Eastham, G. R., Poliakoff, M., and Huddle, T. A. (2009). Method of Producing Arcylic and Methacrylic Acid. Patent No US8933179B2. Lucite International UK Ltd.

Johnson, D. W., Eastham, G. R., Poliakoff, M., and Huddle, T. A. (2012). Process for the Production of Methacrylic Acid and Its Derivatives and Polymers Produced Therefrom. Patent No US20150094438A1. Lucite International UK Ltd.

Kim, S., Clomburg, J. M., and Gonzalez, R. (2015). Synthesis of medium-chain length (C6-C10) fuels and chemicals via $\beta$-oxidation reversal in Escherichia coli. J. Ind. Microbiol. Biotechnol. 42, 465-475. doi: 10.1007/s10295-0151589-6

Kimura, E. (2003). Metabolic engineering of glutamate production. Adv. Biochem. Eng. Biotechnol. 79, 37-57. doi: 10.1007/3-540-45989-8_2

Krull, S., Eidt, L., Hevekerl, A., Kuenz, A., and Prüße, U. (2017b). Itaconic acid production from wheat chaff by Aspergillus terreus. Process Biochem. 63, 169-176. doi: 10.1016/j.procbio.2017.08.010

Krull, S., Hevekerl, A., Kuenz, A., and Prüße, U. (2017a). Process development of itaconic acid production by a natural wild type strain of Aspergillus terreus to reach industrially relevant final titers. Appl. Microbiol. Biotechnol. 101, 4063-4072. doi: 10.1007/s00253-017-8192-x

Kuenz, A., and Krull, S. (2018). Biotechnological production of itaconic acidthings you have to know. Appl. Microbiol. Biotechnol. 102, 3901-3914. doi: $10.1007 /$ s00253-018-8895-7
Kühner, S. (2013). Feedstock Costs. Deliverable D1 1. Available online at: http:// www.bioboost.eu/uploads/files/bioboost_d1.1-syncom_feedstock_cost-vers_ 1.0-final.pdf

Kurteva-Yaneva, N., Zahn, M., Weichler, M. T., Starke, R., Harms, H., Müller, R. H., et al. (2015). Structural basis of the stereospecificity of bacterial B12dependent 2-hydroxyisobutyryl-CoA mutase. J. Biol. Chem. 290, 9727-9737. doi: $10.1074 /$ jbc.M115.645689

Lam, F. H., Ghaderi, A., Fink, G. R., and Stephanopoulos, G. (2014). Biofuels. Engineering alcohol tolerance in yeast. Science 346, 71-75. doi: $10.1126 /$ science. 1257859

Lang, K., Buehler, K., and Schmid, A. (2015). Multistep synthesis of (S)3-hydroxyisobutyric acid from glucose using Pseudomonas taiwanensis VLB120 B83 T7 catalytic biofilms. Adv. Synth. Catal. 357, 1919-1927. doi: 10.1002/adsc.201500205

Lang, K., Zierow, J., Buehler, K., and Schmid, A. (2014). Metabolic engineering of Pseudomonas sp. strain VLB120 as platform biocatalyst for the production of isobutyric acid and other secondary metabolites. Microb. Cell Fact. 13:2. doi: 10.1186/1475-2859-13-2

Lansing, J. C., Murray, R. E., and Moser, B. R. (2017). Biobased methacrylic acid via selective catalytic decarboxylation of itaconic acid. ACS Sustain. Chem. Eng. 5, 3132-3140. doi: 10.1021/acssuschemeng.6b02926

Le Nôtre, J., Witte-van Dijk, S. C. M., van Haveren, J., Scott, E. L., and Sanders, J. P. M. (2014). Synthesis of bio-based methacrylic acid by decarboxylation of itaconic acid and citric acid catalyzed by solid transition-metal catalysts. ChemSusChem 7, 2712-2720. doi: 10.1002/cssc.2014 02117

Lin, P. P., Jaeger, A. J., Wu, T. Y., Xu, S. C., Lee, A. S., Gao, F., et al. (2018). Construction and evolution of an Escherichia coli strain relying on nonoxidative glycolysis for sugar catabolism. Proc. Natl. Acad. Sci. U.S.A. 115, 3538-3546. doi: $10.1073 /$ pnas. 1802191115

Lipscomb, T. E. W., Lynch, M. D., and Gill, R. T. (2011). Methods, Systems and Compositions for Increased microorganism Tolerance to and Production of 3-Hydroxypropionic Acid (3- $h$ p). Patent No US8883464B2. Cargill, Inc., University of Colorado at Boulder.

Lipscomb, T. W., Lipscomb, M. L., and Gill, R. T. (2012). "Metabolic engineering of recombinant E. coli for the production of 3-hydroxypropionate," in Engineering Complex Phenotypes in Industrial Strains, ed R. Patnaik (John Wiley \& Sons, Inc). doi: 10.1002/9781118433034

Liu, C.-G., Xiao, Y., Xia, X. X., Zhao, X. Q., Peng, L., Srinophakun, P., et al. (2019). Cellulosic ethanol production: progress, challenges and strategies for solutions. Biotechnol. Adv. 37, 491-504. doi: 10.1016/j.biotechadv.2019. 03.002

Lynch, M., Louie, M., Copley, S., and Spindler, E. (2014). Microorganisms and Methods for the Production of Fatty Acids and Fatty Acid Derived Products. Patent No US10337038B2. Cargill, Inc.

Macho, V., Králik, M., Chromá, V., Cingelová, J., and Mikulec, J. (2004). The oxidative dehydrogenation of methyl isobutyrate to methyl methacrylate. Petroleum and Coal. 46, 69-80.

Madison, L. L., and Huisman, G. W. (1999). Metabolic engineering of Poly(3Hydroxyalkanoates): from DNA to plastic. Microbiol. Mol. Biol. Rev. 63, 21-53. doi: 10.1128/MMBR.63.1.21-53.1999

Mahboub, M. J. D., Dubois, J.-L., Cavani, F., Rostamizadeh, M., and Patience, G. S. (2018). Catalysis for the synthesis of methacrylic acid and methyl methacrylate. Chem. Soc. Rev. 47, 7703-7738. doi: 10.1039/C8CS $00117 \mathrm{~K}$

Marx, A., Poetter, M., Buchholz, S., May, A., Siegert, H., Alber, B., et al. (2016). Process for Preparing Methacrylic Acid or Methacrylic Esters. Patent No US20100291644A1. Evonik Roehm GmbH

Massey, L. K., Sokatch, J. R., and Conrad, R. S. (1976). Branchedchain amino acid catabolism in bacteria. Bacteriol. Rev. 40, 42-54. doi: 10.1128/MMBR.40.1.42-54.1976

McDaniel, E. L., and Young, H. S. (1963). Catalytic dehydrogenation of methyl isobutyrate to methyl methacrylate over alumina catalysts. Industr. Eng. Chem. Product Res. Dev. 2, 287-292. doi: 10.1021/i3600 $08 \mathrm{a} 009$

Mori, K., and Toraya, T. (1999). Mechanism of reactivation of coenzyme B12dependent diol dehydratase by a molecular chaperone-like reactivating factor. Biochemistry 38, 13170-13178. doi: 10.1021/bi9911738 
Mukhopadhyay, A. (2015). Tolerance engineering in bacteria for the production of advanced biofuels and chemicals. Trends Microbiol. 23, 498-508. doi: 10.1016/j.tim.2015.04.008

Murakami, Y., Kawata, A., Suzuki, S., and Fujisawa, S. (2019). Cytotoxicity and pro-inflammatory properties of aliphatic Alpha, Beta-unsaturated acid and ester monomers in RAW264.7 cells and their chemical reactivity. In vivo 33, 313-323. doi: 10.21873/invivo.11477

Mustafa, B., and Balat, H. (2009). Recent trends in global production and utilization of bio-ethanol fuel. Appl. Energy 86, 2273-2282. doi: 10.1016/j.apenergy.2009.03.015

Nagai, K., and Ui, T. (2004). Trends and future of monomer-MMA technologies. Sumitomo Chem. 2, 4-13.

NREL (2013). NREL Proves Cellulosic Ethanol Can Be Cost Competitive (Fact Sheet).

Parimi, N. S., Durie, I. A., Wu, X., Niyas, A. M. M., and Eiteman, M. A. (2017). Eliminating acetate formation improves citramalate production by metabolically engineered Escherichia coli. Microb. Cell Fact. 16:114. doi: 10.1186/s12934-017-0729-2

Pirmoradi, M., and Kastner, J. R. (2017). Synthesis of methacrylic acid by catalytic decarboxylation and dehydration of carboxylic acids using a solid base and subcritical water. ACS Sustain. Chem. Eng. 5, 1517-1527. doi: 10.1021 /acssuschemeng.6b02201

Plaga, W., Vielhaber, G., Wallach, J., and Knappe, J. (2000). Modification of Cys-418 of pyruvate formate-lyase by methacrylic acid, based on its radical mechanism. FEBS Lett. 466, 45-48. doi: 10.1016/S0014-5793(99)0 $1752-4$

Rajni, H. K., Tornvall, U., Gustafsson, L., and Boerjesson, P. (2006). Industrial biotechnology for the production of bio-based chemicals - a cradle-to-grave perspective. TRENDS Biotechnol. 25, 119-124. doi: 10.1016/j.tibtech.2007.01.001

Reinecke, L., Schaffer, S., Marx, A., Poetter, M., and Haas, T. (2011). Recombinant Cell Producing 2-Hydroxyisobutyric Acid. Patent No US20110171702A1. Evonik Roehm GmbH

Rendina, G., and Coon, M. J. (1957). Enzymatic hydrolysis of the coenzyme a thiol esters of $\beta$-hydroxypropionic and $\beta$-hydroxyisobutyric acids. J. Biol. Chem. $225,523-534$.

Risso, C., Van Dien, S. J., Orloff, A., Lovley, D. R., and Coppi, M. V. (2008). Elucidation of an alternate isoleucine biosynthesis pathway in Geobacter sulfurreducens. J. Bacteriol. 190, 2266-2274. doi: 10.1128/JB. 01841-07

Rohde, M.-T., Tischer, S., Harms, H., and Rohwerder, T. (2017). Production of 2-Hydroxyisobutyric Acid from Methanol by Methylobacterium extorquens AM1 Expressing (R)-3-Hydroxybutyryl Coenzyme A-Isomerizing Enzymes. Appl. Environ. Microbiol. 83:e02622-16. doi: 10.1128/AEM. 02622-16

Rohwerder, T., Breuer, U., Benndorf, D., Lechner, U., and Müller, R. H. (2006). The alkyl tert-butyl ether intermediate 2-hydroxyisobutyrate is degraded via a novel cobalamin-dependent mutase pathway. Appl. Environ. Microbiol. 72, 4128-4135. doi: 10.1128/AEM.00080-06

Rohwerder, T., and Müller, R. H. (2010). Biosynthesis of 2-hydroxyisobutyric acid (2-HIBA) from renewable carbon. Microb. Cell Fact. 9:13. doi: $10.1186 / 1475-2859-9-13$

Rosales-Calderon, O., and Arantes, V. (2019). A review on commercialscale high-value products that can be produced alongside cellulosic ethanol. Biotechnol. Biofuels 12:240. doi: 10.1186/s13068-0191529-1

Sale, K. (2019). EPCA'19: Roehm to build 250,000 tonne/year MMA plant in US Gulf Coast, start-up by 2024. Icis. Available online at: https://www.icis.com/ explore/resources/news/2019/10/08/10426307/epca-19-roehm-to-build-250000-tonne-year-mma-plant-in-us-gulf-coast-start-up-by-2024 (accessed Febraury 17, 2020).

Soare, A. (2013). Cellulosic Chemicals and Fuels Race to Compete with First-Gen Sugar Economics. https://members.luxresearchinc.com/research/report/12706 (accessed Febraury 17, 2020).

Soucaille, P., and Boisart, C. (2011). Enzymatic Production of 2-HydroxyIsobutyrate (2-hiba). Patent No US20110151530A1. Metabolic Explorer SA.

Steiger, M. G., Blumhoff, M. L., Mattanovich, D., and Sauer, M. (2013). Biochemistry of microbial itaconic acid production. Front. Microbiol. 4:23. doi: $10.3389 /$ fmicb. 2013.00023
Taylor, R., Nattrass, L., Alberts, G., Robson, P., Chudziak, C., Bauen, A., et al. (2015). From the Sugar Platform to Biofuels and Biochemicals. Final report for the European Commission Directorate-General Energy.

Tehrani, H. H., Becker, J., Bator, I., Saur, K., Meyer, S., Lóia, A. C. R., et al. (2019). Integrated strain-and process design enable production of $220 \mathrm{~g} \mathrm{~L}-1$ itaconic acid with Ustilago maydis. Biotechnol. Biofuels 12, 1-11. doi: 10.1186/s13068-019-1605-6

The Chemical Engineer (2008). Evonik develops new process for methyl methacrylate. Focus Catal. 2008, 6-7. doi: 10.1016/S1351-4180(08) 70573-7

Valdehuesa, K. N. G., Liu, H., Nisola, G. M., Chung, W. J., Lee, S. H. et al. (2013). Recent advances in the metabolic engineering of microorganisms for the production of 3-hydroxypropionic acid as C3 platform chemical. Appl. Microbiol. Biotechnol. 97, 3309-3321. doi: 10.1007/s00253-013$4802-4$

Van Dien, S. (2013). From the first drop to the first truckload: commercialization of microbial processes for renewable chemicals. Curr. Opin. Biotechnol. 24, 1061-1068. doi: 10.1016/i.copbio.2013.03.002

Volker, T., and Schindelmann, E. (1969). Preparation of Methacrylic Compounds by Dehydration of Alpha - Hydroxybutyric Acid Compounds. Patent No US3487101A. Lonza Ltd.

Wang, J., Wang, J., Tai, Y. S., Zhang, Q., Bai, W., Zhang, K., et al. (2018). Rerouting carbon flux for optimized biosynthesis of mesaconate in Escherichia coli. Appl. Microbiol. Biotechnol. 102, 7377-7388. doi: 10.1007/s00253-0189135-x

Wang, J., and Zhang, K. (2015). Production of mesaconate in Escherichia coli by engineered glutamate mutase pathway. Metab. Eng. 30, 190-196. doi: 10.1016/j.ymben.2015.06.001

Wang, L., Chauliac, D., Moritz, B. E., Zhang, G., Ingram, L. O., Shanmugam, K. T., et al. (2019). Metabolic engineering of Escherichia coli for the production of butyric acid at high titer and productivity. Biotechnol. Biofuels 12:62. doi: 10.1186/s13068-019-1408-9

Webb, J., Springthorpe, V., Rossoni, L., Minde, D. P., Langer, S., Walker, H., et al. (2019). Systems analyses reveal the resilience of Escherichia coli physiology during accumulation and export of the nonnative organic acid citramalate. mSystems 4:e0187-19. doi: 10.1128/mSystems. 00187-19

Webb, J. P., Arnold, S. A., Baxter, S., Hall, S. J., Eastham, G., Stephens, G., et al. (2018). Efficient bio-production of citramalate using an engineered Escherichia coli strain. Microbiology 164, 133-141. doi: 10.1099/mic.0.0 00581

Wendisch, V. F., Jorge, J. M. P., Pérez-García, F., and Sgobba, E. (2016). Updates on industrial production of amino acids using Corynebacterium glutamicum. World J. Microbiol. Biotechnol. 32:105. doi: 10.1007/s11274-0162060-1

Wilhelm Gruber, D., and Ginter Schröder, O.-R. (1983). Process for Producing Methacrylic Acid by Oxidative Dehydration of Isobutyric Acid and Catalyst Therefor. Patent No US4370490A. Evonik Roehm GmbH. Available online at: https://patents.google.com/patent/US4370490A/en.

Witczak, T., Grzesik, M., Skrzypek, J., and Witczak, M. (2010). Liquidphase esterification of methacrylic acid with methanol catalyzed by heteropolyacid. Int. J. Chem. Reactor Eng. 8, 1-6. doi: 10.2202/1542-6580. 2128

Wu, X., and Eiteman, M. A. (2016). Production of citramalate by metabolically engineered Escherichia coli. Biotechnol. Bioeng. 113, 2670-2675. doi: 10.1002/bit.26035

Xiong, M., Yu, P., Wang, J., and Zhang, K. (2015). Improving engineered Escherichia coli strains for high-level biosynthesis of isobutyrate. Aims Energy 2, 60-74. doi: 10.3934/bioeng.2015.2.60

Yaneva, N., Schuster, J., Schäfer, F., Lede, V., Przybylski, D., Paproth, T., et al. (2012). Bacterial Acyl-CoA mutase specifically catalyzes coenzyme B12-dependent isomerization of 2-hydroxyisobutyryl-CoA and (S)-3-hydroxybutyryl-CoA. J. Biol. Chem. 287, 15502-15511. doi: 10.1074/jbc.M111.314690

Yim, H., Haselbeck, R., Niu, W., Pujol-Baxley, C., Burgard, A., Boldt, J., et al. (2011). Metabolic engineering of Escherichia coli for direct production of 1,4-butanediol. Nat. Chem. Biol. 7, 445-452. doi: 10.1038/nchembio. 580 
Youngs, H., and Somerville, C. (2012). Development of feedstocks for cellulosic biofuels. F1000 Biology Reports 4:10. doi: 10.3410/B4-10

Yu, A.-Q., Juwono, N. K. P., Foo, J. L., Leong, S. S. J., and Chang, M. W. (2016). Metabolic engineering of Saccharomyces cerevisiae for the overproduction of short branched-chain fatty acids. Metabolic Eng. 34, 36-43. doi: 10.1016/j.ymben.2015.12.005

Zhang, K., Woodruff, A. P., Xiong, M., Zhou, J., and Dhande, Y. K. (2011). A synthetic metabolic pathway for production of the platform chemical isobutyric acid. ChemSusChem 4, 1068-1070. doi: 10.1002/cssc.201100045

Zhao, C., Cui, Z., Zhao, X., Zhang, J., Zhang, L., Tian, Y., et al. (2019). Enhanced itaconic acid production in Yarrowia lipolytica via heterologous expression of a mitochondrial transporter MTT. Appl. Microbiol. Biotechnol. 103, 2181-2192. doi: 10.1007/s00253-019-09627-z
Conflict of Interest: ML has a financial interest in DMC Biotechnologies, Inc.

The remaining authors declare that the research was conducted in the absence of any commercial or financial relationships that could be construed as a potential conflict of interest.

Copyright (c) 2020 Lebeau, Efromson and Lynch. This is an open-access article distributed under the terms of the Creative Commons Attribution License (CC BY). The use, distribution or reproduction in other forums is permitted, provided the original author(s) and the copyright owner(s) are credited and that the original publication in this journal is cited, in accordance with accepted academic practice. No use, distribution or reproduction is permitted which does not comply with these terms. 